\title{
Saving Face: Inclusive Communication With College Students With Disabilities Using Politeness And Face Negotiation
}

\author{
Karen A. Myers, Saint Louis University, USA \\ Christine Spudich, Saint Louis University, USA \\ Dimana Spudich, Saint Louis University, USA \\ Sarah E. Laux, Southern Illinois University Edwardsville, USA
}

\begin{abstract}
Have I offended anyone today? Have I been insensitive? Creating welcoming inclusive environments for students with and without disabilities is a higher education imperative. The academy strives to create diverse and welcoming atmospheres for students and educators and employ social justice and face saving measures to encourage respectful communication and discourage discriminatory behaviors. With the increase of college students with disabilities, professionals need to be comfortable and confident in their communication tactics. Applying politeness and face-negotiation theories to the communication preferences and behaviors of college students with disabilities, this article offers practice-oriented applications for respectful inclusive communication.
\end{abstract}

Keywords: Face Negotiation; Politeness; Inclusive Communication; College Students; Disabilities

\section{INTRODUCTION}

Q tudent affairs professionals are trained to support and model core values of inclusion and social justice. They are encouraged to provide welcoming environments to all students, including those with disabilities. Disability legislation has provided higher education opportunities for students with disabilities who previously may not have considered college as an option. This increase in college students with disabilities intensifies opportunities for students with and without disabilities to interact with one another. The Americans with Disabilities Act (ADA - Americans with Disabilities Act, 1990), ADA Amendments Act (ADAAA - Americans with Disabilities Act Amendments Act, 2008), and the Higher Education Opportunity Act (Higher Education Opportunity Act, 2008) provide people with disabilities equal opportunities to participate in and contribute to society, and such disability legislation has had profound effects on the lives of students with disabilities by providing them with new access to postsecondary education (Johnson \& Fox, 2003). Due to the growing enrollment of students with disabilities in higher education, including U.S. military veterans (Miles, 2010) using the Post-911 GI Bill (Grossman, 2009), there is an ever-pressing need for further research and scholarships relating to college students with disabilities (Snyder \& Dillow, 2010).

The purpose of this article is to address communication preferences of college students with disabilities through Politeness and Face-Negotiation Theories. The paper begins with the discussion of communication and social interaction related to students with disabilities, followed by an explanation of Politeness and Face-Negotiation Theories and their application to two existing national studies. The article concludes with recommendations for student affairs professionals regarding inclusive communication practices. 


\section{COMMUNICATION AND STUDENTS WITH DISABILITIES}

Communication is defined as "the act of imparting or transmitting information, both verbally and nonverbally" in which the exchange of gestures, thoughts and attitudes are conveyed (Charlton, Dearing, Berry \& Johnson, 2008, p. 383). In order for effective communication to occur and knowing that individuals define "effective" in their own terms, communication preferences between individuals have to be acknowledged (de Vries, Bakker-Pieper, Siberg, van Gameren \& Vlug, 2009). Many define communication preferences as certain skills or behaviors that make people who they are and influence how they communicate (Hanke, 2009).

For this article, communication preferences are defined as methods or approaches that individuals favor for communicating, which affects how others react to and perceive them (Edmondson, 2009). Researchers note that such preferences vary depending upon the context of the message, the target of the communication, and the characteristics of the medium (Lightfoot, 2009). Scholars discover that when negative occurrences are experienced through communication or if individuals deliver distressing news, communication preferences relate to the content of the message, the setting and the use of supportive elements such as empathy, respect, emotional support, consideration and concern via verbal and nonverbal communication (Fujimori, Parker, Akechi, Sakano, Baile, \& Uchitomi, 2007). Because communication preferences vary greatly depending on setting and context, the question is raised regarding how such preferences are managed during communication of individuals with disabilities.

It is a well-known fact that individuals have and recognize their own communication preferences (Edmondson, 2009; Richardson \& Woodley, 2001). However, how does the dominant society, in this case those without disabilities, consider the communication preferences of individuals with disabilities during conversation? Further, how do the attitudes and behaviors of individuals without disabilities toward those with disabilities impact and shape the communication preferences of those individuals with disabilities? Rauscher and McClintock (1997) described a lack of knowledge and awareness that such communication preferences exist and should be discussed as a form of disability oppression and ableism that discriminates and excludes individuals with disabilities.

According to Raue and Lewis (2011), 88 percent of two- and four-year Title IV degree-granting postsecondary institutions reported enrolling students with disabilities. Further, 99 percent of public two- and four-year institutions and 100 percent of medium and large institutions reported enrolling students with disabilities. Of those institutions, 67 percent report enrolling students with visual disabilities, reflecting 3 percent of all students enrolled in post-secondary institutions. Although the population of students with disabilities has increased significantly over the last 40 years (National Center for Education Statistics, 2006), students with visual disabilities are still less likely to complete their undergraduate degree requirements than students without disabilities (Madaus, 2000; Wagner, D'Amico, Marder, Newman, \& Blackorby, 1992). One main reason for this phenomenon includes managing the stigma of being visibly different from other students or defined by their disability through the academic accommodations application and utilization processes (Tripoli, Mellard, \& Kurth, 2004; Johnson \& Fox, 2003; Ash, Bellew, Davies, Newman, \& Richardson, 1997; Barga, 1996). As such, individuals with disabilities often are viewed as a culture, and, therefore, their communications with individuals with or without disabilities are considered forms of intercultural communication. Further, a subculture of specific disabilities, such as visual disabilities, consists of subsets such as legally blind and totally blind (Myers, 2009; Emery \& Wiseman, 1987).

The onset and presence of a disability also affects opportunities for social interactions and communication between students with disabilities and those without disabilities (Correa-Torres, 2008; Bruce, Godbold, \& Naponelli-Gold, 2004). In addition, the level of blindness and onset of the visual disability affects students' communication needs. Students with visual disabilities with an onset at birth may have different communication needs than students with visual disabilities who experienced a later onset in life (Myers, 2009). According to Roy and MacKay (2002), "commentators and researchers with visual disabilities have noted that sighted people have more difficulty understanding low vision than blindness. This lack of understanding may severely affect the selfperception of people with low vision" (p. 254). Because the onset of disability affects individuals' adjustment to the disability (Tuttle, 1984), their communication preferences may be affected. 


\section{POLITENESS}

Politeness Theory is originated with the concept of "face" having a central role in the theory. Individuals wish to be perceived as competent, and this phenomenon is represented using the term, face. In theoretical literature, face refers to an individual's public image, and describes how an individual wants to be viewed publicly (Goffman, 1967; Goffman, 1959). Noting how Goffman viewed face, Brown and Levinson (1987) advanced Goffman's concept of face and described face as fundamentally belonging to the person, thus defining face as the respect an individual has and preserving or keeping that respect in public or private situations (Brown \& Levinson, 1978).

Face is present during communication (Lim \& Bowers, 1991), and individuals have and maintain two kinds of face: positive face, the feeling of being included, connected, appreciated, and respected (Longcope, 1995), and negative face, feeling free from constraint and remaining independent (Duthler, 2006). While people work to maintain face, certain acts, known as face-threatening acts can intrinsically threaten face. Acts, such as criticisms, disagreements and interruptions are intended to be acceptable, but the very nature of these acts often threatens the other person's face (Brown \& Levinson, 1978).

Politeness emphasizes phrasing communication to help save face for others, to show respect and esteem for the face of others (Holtgraves \& Joong-Nam, 1992), and take into consideration the feelings of others (Brown \& Levinson, 1978). College students with visual disabilities may have to adjust their communication in terms of politeness to show respect and esteem for the face of others. Because college students with visual disabilities are considered a type of culture, the authors speculate that specific Politeness elements may connect to students' communication experiences. The application of Politeness Theory offers an interesting perspective to the topic of communication preferences of college students with visual disabilities.

\section{FACE NEGOTIATION}

Face Negotiation Theory explains how individuals utilize "face" in order to achieve efficient and effective communication. Ting-Toomey's original conception of the theory relates to the notion of culture and conflict in how individuals communicate, and proposes the underlying assumption that face is an explanatory mechanism for different face work and conflict behaviors (Ting-Toomey, 1988). Ting-Toomey also believes that how individuals construe their sense of self is a primary factor in conflict management interactions (Ting-Toomey, Oetzel \& YeeJung, 2001; Ting-Toomey \& Kurogi, 1998). While the theory addresses elements of culture and conflict management, the key component of this theory utilized in this article pertains to how people of every culture negotiate "face" during conversations.

The term "face" describes people's envisioned self in society. Ting-Toomey defines face as "the projected image of one's self in a relational situation" and argues that face represents an individual's claimed sense of positive image in the context of social interaction (Ting-Toomey, 1988, p. 215). Facework refers to the communicative strategies that individuals use to enact self-face and uphold, support or challenge another person's face (TingToomey \& Kurogi, 1998). Ting-Toomey regards face as "a tell-tale sign that we feel awkward, embarrassed, ashamed or proud" (Ting-Toomey \& Kurogi, 1998, p. 187). In this theory, face-restoration is defined as the facework strategy used to preserve autonomy and defend against loss of personal freedom, and face-saving and facegiving strategies defend and support another person's need for inclusion (Ting-Toomey, 1988).

Because of the intercultural communication that occurs among students with and without disabilities in the higher education setting, the use of face-negotiation as a communication preference is considered a cross-cultural phenomenon (Oetzel, Ting-Toomey, Chew-Sanchez, Harris, Wilcox \& Stumpf, 2003). Face-negotiation is typically used in conflict situations, such as verbal conflict, which may easily arise during students' many conversations on a college campus. This is especially apparent during emotional and vulnerable situations when the students' identities are called into question (Ting-Toomey, 2004). 


\section{POLITENESS AND FACE NEGOTIATION APPLIED}

Considering the concepts of politeness and face negotiation as they relate to people with disabilities, the theories were applied to two existing studies. The first study consisting of interviews with college students who were blind or had low vision revealed three emerging themes: respect, comfort and awareness. The second study revealed that many students without disabilities hold negative attitudes and behaviors toward students with disabilities. By applying the communication theories of Politeness and Face Negotiation to both studies, it is shown that elements of "politeness," such as respect and value, connect all students' experiences in post-secondary settings, and face-saving and face-giving measures are used in effective communication.

\section{Study A}

The first study (Study A) (Myers 2009; Myers \& Bastian, 2010) focused on the communication preferences students with visual disabilities have and utilize when conversing with others without disabilities. This study consisted of focused interviews with 35 college students (ages 19 to 70 years of age) with visual disabilities who were totally blind, i.e., unable to see, or legally blind (i.e., visual acuity of 20/200 or poorer or visual field less than 20 degrees). Two characteristics that clearly surfaced related to disability onset and readiness to disclose. Sixteen (16) of the participants had congenital visual disabilities with the onset occurring at birth and the remaining 19 participants experienced a loss in their sight later in life due to accident, degenerative disease or illness. Those who became suddenly blind described their coping stages ranging from anger to denial to total acceptance.

Three themes emerged from the data: respect for others, comfort during interactions, and awareness of disability issues. The theme of respect relates to greetings, welcoming remarks, inappropriate behavior and the acknowledgement of common courtesy during communication. Comfort relates to the participants' strives for a comfortable setting, which is most likely obtained through honest communication in which accommodation inquires are made. Descriptive responses and humor are utilized, and persons with disabilities take it upon themselves to "break the ice" in efforts to set a comfortable tone when conversing with individuals with sight. The theme of awareness relates to false assumptions, and demonstrating empathy and sensitivity of another person's needs. Awareness also pertains to the benefit that disability awareness training brings forth in order for people to communicate more effectively with individuals with disabilities.

Among the interviews, a frequent response from the participants related to their acceptance of the disability. These findings are applied to Brown and Levinson's (1978) Politeness Theory and Ting-Toomey's (1988) Face-Negotiation Theory, and while both theories describe the concept of "face," separate application of the theories allows exploration of different elements within the students' interviews. Elements such as comfort, mutual respect and humor are explored through the Politeness Theory discussion, and communication differences, facesaving, and disability coping are explored through Face-Negotiation Theory (see Discussion section below).

\section{Study B}

The second study (Study B) (Myers, Jenkins, \& Pousson, 2009) focused on understanding the attitudes and behaviors of students without disabilities toward their peers with disabilities. A total of 1,509 completed a webbased survey. In addition to demographic information, students responded to a series of nine questions regarding a student's comfort level being around students with physical, psychological, and learning disabilities, as well as the student's perception of their friends' comfort level and the comfort level of the typical college student. The final 12 survey questions dealt with harassment, avoidance, and witnessed harassment of students with disabilities on campus.

The findings of Study B showed that a number of students perceived negative attitudes and behaviors toward students with disabilities on their campuses. Forty-nine (49) students reported using harmful or inappropriate remarks toward students with disabilities on their campuses and 70 students with disabilities reported personally experiencing harmful or inappropriate remarks on campus because of their disabilities. Four hundred fifty-nine (459) students reported witnessing harmful or inappropriate remarks made toward their college peers with disabilities, and 91 of those students reported witnessing physical harassment made toward students with disabilities 
on their campuses. Nearly 33 percent (495 students) reported witnessing other students avoiding students with disabilities on their campuses, and 174 students with disabilities reported purposely avoiding other college students with disabilities. Only 85 students reported being "very comfortable" or "comfortable" witnessing this mistreatment (verbal and/or physical harassment) of students with disabilities on their campuses while 189 students reported thinking the typical college student on their campus would be "very comfortable" or "comfortable" witnessing the mistreatment of students with disabilities.

\section{DISCUSSION OF THE THEORETICAL APPLICATIONS}

Upon applying Politeness Theory and Face-Negotiation Theory to each study's results, elements of face negotiation and politeness are clearly present and necessary to combat individuals' attitudes and behaviors toward those with disabilities. As shown through the results of Study B, nearly one-third of the surveyed college students have witnessed other students making harmful or inappropriate remarks toward students with disabilities and purposely avoid students with disabilities on their campuses. In an attempt to combat these behaviors and attitudes, the college students interviewed in Study A manage face-saving and face-giving efforts, strive to make others feel comfortable, and incorporate humor, mutual respect, and advice for future situations in their communication. TingToomey (1988) expresses "face" as a metaphor for public self-image and reflecting the way individuals want others to see and treat them. This concept of "face" is also present in the students' communication.

Disability stereotyping and oppression occur when people have negative attitudes toward students with disabilities because of their lack of knowledge about disability (Burgstahler, 2003; Evans \& Herriott, 2009). The lack of awareness creates uneasiness when communicating with individuals with disabilities. A nationwide survey of graduate students revealed that the majority of respondents do not know what steps to take to ensure inclusion of students with disabilities and believe that some type of disability awareness education in their degree programs is needed (Myers, 2008). Throughout the interviews, participants of Study A expressed their desire for respect and comfort during communication and discussed the importance of people having an awareness of disability issues as a main factor for effective communication between persons with and without visual disabilities. This aligns with the Politeness Theory that emphasizes utilizing comfort, respect, and humor among the communication preferences of those with visual disabilities. However, research continues to show that society views individuals with disabilities as being fundamentally different from themselves (Linton, 2006). A recent study on student veterans, for example, showed students with Post Traumatic Stress Disorder (PTSD) symptoms reported more feelings of alienation on campus (Elliot, Gonzalez, \& Larsen, 2011).

Showing respect and treating individuals with disabilities equitably is imperative in daily communication (Johns \& McGrath, 2008). Respect is regarded as something owed to all individuals, and giving and having respect for all individuals requires that society make efforts to look at the world from the point of view of others, not solely from one's own perspective (Vorhaus, 2006).

All the participants in Study A (i.e., students with visual disabilities) expressed concern over making sure people without visual disabilities feel comfortable around them and respect their worth and ability. Achieving and maintaining a significant comfort level on the part of both communicators was high on the interviewees list of priorities (Myers, 2009). Participants' feelings of comfort in communication are associated with the positive and negative elements of feeling connected, appreciated, respected and independent. In their desire to maintain positive and negative face, participants reported taking it upon themselves to 'break the ice' and set a comfortable tone when conversing with individuals with sight.

Additionally, each participant in Study A found humor (often self-deprecating jokes or one-liners) to be essential for putting others at ease. Participants emphasized the importance of putting others at ease, respecting others' time, and understanding others' feelings of potential anxiety toward his/her disability. According to Myers (2009), "laughing at themselves and their own 'faux pas,' making light of their visual disabilities, and bringing attention to themselves as human beings rather than persons with disabilities were common communication techniques used by the participants" (p. 120). Holmes (2000) emphasized humor to be a positive ingredient in communication interactions and politeness conveys a sense of collegiality while de-emphasizing power imbalances. Additional research shows that humor serves as a catharsis for coping, allowing individuals with disabilities to 
achieve new perspectives on their own circumstances (Reid, Stoughton, \& Smith, 2006). Haller (2003) also states that comedy is a "universal bridge" (p. 9) in communication.

By using humor to comfort, individuals with visual disabilities direct and adapt their communication in terms of politeness by phrasing communication to show respect and esteem for the "face" of others. The participants interviewed in Study A maintain that they negotiate "face" during conversations and continually manage face-giving and face-saving strategies to put those without disabilities at ease. Participants often were disappointed or bothered by the behaviors and attitudes they experienced on college campuses because it hindered their attempts to negotiate face. The annoyances consisted of ignoring, shouting, over-accommodating, using politically incorrect language, becoming upset when nonverbal cues were missed, and assuming ignorance (Myers \& Bastian, 2010). However, the participants manage these negative behaviors by maintaining a proactive approach to help others "save face." They attempt to raise awareness by educating others on how to behave in future situations. By teaching better behaviors, they help others "save face", minimizing embarrassment for both parties and increasing awareness of their own disabilities.

Nearly all of the participants in Study A believed it is their responsibility to "break the ice" and make others feel comfortable. As previously mentioned, humor, a communication preference for many with visual disabilities, is considered a useful tool for face-giving.

\section{IMPLICATIONS FOR HIGHER EDUCATION PRACTICES}

Although evidence shows the population of students with disabilities enrolling in higher education is continually increasing (U.S. Census, 2010), students with disabilities remain underrepresented in the nation's college population because of low expectations, poor high school preparation, lack of transition planning, and lack of support services (Garrison-Wade \& Lehmann, 2009). With this increase, faculty and staff must protect the privacy rights and dignity of students with disabilities, and exercise sensitivity to those students who may be reluctant to identify themselves as having a disability in class (Johns \& McGrath, 2008). Due to these reasons, students with disabilities may be hesitant to enroll in specific classes, causing other students without disabilities to lack experience and contact with them and may feel unsure about how to behave and communicate. Based on these occurrences and lack of disability awareness, students with disabilities feel the responsibility to utilize facenegotiation and politeness among students without disabilities.

Through awareness training, administrators, faculty and staff gain valuable knowledge about eliminating attitudinal barriers, dispelling myths, reducing fear, being sensitive to individual needs, and communicating effectively with people who are blind or have low vision (Myers, 2009; Myers \& Bastian, 2010). Students regularly encounter physical barriers and discouraging attitudes on campuses, and disability education and self-advocacy preparation are two ways to foster an increased awareness about disability (McCarthy, 2007). Educating students about the history of disability can increase their comfort level and communication with students with disabilities. Self-advocacy skills help students with disabilities learn that advocacy is a relational process, and, as their selfunderstanding grows, so does the potential and responsibility for self-advocacy and how they communicate their advocacy among those without disabilities (McCarthy, 2007).

\section{Advocacy}

Most can identify their own needs and interests, and have the opportunity to make choices and carry out those choices in order to become self-determined (Field, 1996; Fiedler \& Danneker, 2007). Yet, individuals may not entirely understand what encompasses self-advocacy, and how self-advocacy relates to communication. Selfadvocacy consists of such characteristics as basic human, civil and legal rights, speaking out for one's beliefs, understanding of self and exemplifying leadership, dignity and collaboration (Test, Fowler, Wood, Brewer \& Eddy, 2005). Many scholars believe that to advocate for themselves effectively, students must recognize their own likes, dislikes, needs, strengths and limitations, and be able to express those within various settings (Schreiner, 2007).

During times when students have to advocate for themselves, communication is present. Communicating one's advocacy includes being assertive, persuading and listening (Fiedler \& Danneker, 2007). Since face is viewed 
as the projected image of one's self in a relational sense (Ting-Toomey, 1988), matters of politeness and facenegotiation are constantly being managed during these exchanges. The findings in Study A highlight how students with visual disabilities feel it their responsibility to utilize humor to negotiate face, make conscious strives for comfort, and dispense polite advice to educate others. Therefore, educators will recognize that during all communicative exchanges, even those in which students advocate for themselves, students are negotiating face and managing politeness in efforts to efficiently and effectively communicate.

\section{Practice-oriented Applications for Inclusive Communication}

For many college students, effective communication occurs in a variety of settings, when students manage challenging intellectual tasks and collaborate in social settings. For college students with disabilities, effective communication is even more complex. Facework and communication preferences play a pivotal role not only in students' communications and interactions, but also with their understanding of others. Politeness Theory principles and Face-Negotiation strategies are present in students' everyday interactions with individuals without disabilities, and demonstrate how the central concept of "face" influenced their communication. However, the role of society is also important and pertains to this article's recommendations.

Moving from the medical (i.e., deficiency) model of disability to the social construction model in which society removes barriers that prevent inclusion is a step toward more effective communication (Jones, 1996). In this context, society takes the responsibility of defining disability and removes the responsibility from the individual. When society looks ahead even further through a social justice lens, it views disability as an expression of human diversity with emphasis on an individual's complete identity, the oppression experienced, and the oppressive contributions of the dominant group without disabilities (Evans \& Herriott, 2009). Higher education, a microcosm of society, holds the same responsibility. While supporting student self-advocacy, postsecondary institutions are encouraged to foster shared responsibility in providing access to students with disabilities and creating a positive learning environment for all students (Baxter Magolda, 1999; Myers, 2009; Myers \& Bastian, 2010). Through selfeducation, communication, advocacy and direct action, the campus community (faculty, administrators and students) can become valued allies of students with disabilities (Evans, Assadi \& Herriott, 2005).

\section{Recommendations For Inclusive Communication}

Based on the results of Study A and Study B, the authors developed 12 recommendations to facilitate effective communication with students with visual and other disabilities. The list concludes with an explanation of Universal Instructional Design, a technique to provide equal access to all students. Although these recommendations are common knowledge to professionals in the field, they may benefit educators and administrators in professional development efforts and in disability awareness training initiatives. The 12 Tips for Effective Inclusive Communication are:

1. Be knowledgeable of the law relative to students with disabilities and higher education.

2. Listen attentively; place an emphasis on listening to what the student says.

3. Make mutual respect an important priority during communication. Follow the golden rule.

4. Ask questions about appropriate accommodations; do not assume the student needs help.

5. Avoid "singling out" students with disabilities or drawing attention to differences.

6. Do not assume a student with a disability is unintelligent, incapable of completing tasks, or unable to comprehend course material.

7. Speak clearly and be descriptive. Avoid pointing and using ambiguous words such as "this," "that," "over here," and "over there."

8. Do not use inappropriate humor. If you are not sure what is inappropriate, please ask first.

9. Verbalize written material displayed on boards, projectors, in PowerPoint presentations, etc.

10. Provide handouts in alternate formats; i.e., large print, Braille, eText, audio, CD.

11. Provide all materials online, preferably in Word documents. (Some screen reader programs have difficulty reading pdf.) Students can then alter font size, color, type, etc. and download and print documents in a format that is readable to them. 
12. Implement Universal Instructional Design (UID) practices. UID principles are used to create programs, services, and accessible curricula for all students regardless of background, learning style, ability or disability (Higbee, 2003; Higbee \& Goff, 2008). For specific UID practices, see Pedagogy and student services for institutional transformation implementation guidebooks at http://www.cehd.umn.edu/passit (Goff \& Higbee, 2008).

\section{CONCLUSION}

As student populations diversify, educational leaders must advocate social justice to ensure that inclusive environments are created for all students. Since the field of disability studies is expanding, educators are discovering new strategies to advance their instruction and service provision. Strategies, such as inclusion and Universal Instructional Design, are increasing awareness of disability and influencing ever-changing views of disability on the college campus. As educators maintain Politeness and Face-Negotiation theories when interacting with students with and without disabilities, they continue to advocate for the understanding, awareness, and acceptance of the social and communicative meanings associated with disabilities in today's society.

\section{AUTHOR INFORMATION}

Karen A. Myers, Ph.D., is associate professor and director of the higher education administration graduate program at Saint Louis University. Recipient of the ACPA College Student Educators International Voice of Inclusion Award, she has been a college teacher and administrator for over 30 years and currently serves on the ACPA Foundation Board of Trustees. She is a writer, researcher, consultant and trainer in the area of disability, author of three disability-related books, and Director and co-originator of the award winning national traveling project, Allies for Inclusion: The Ability Exhibit. E-mail: kmyers11@slu.edu (Corresponding author)

Christine Spudich, M.A., is a doctoral student at Saint Louis University where she is completing her Ph.D. in Education with a concentration in Curriculum and Instruction. Earlier this year she earned ADB status and is finishing her dissertation, which focuses on adult twins' relationship and their same career paths. She has a Master of Arts in Speech Communication and a Bachelor of Science in Elementary Education from Southern Illinois University Edwardsville. She is a presenter at the Mid-Western Educational Research Association and the Central States and Southern States Communication Association conferences and publishes articles in communication and education journals. E-mail: cspudich@slu.edu

Dimana Spudich, M.A., is a doctoral student at Saint Louis University where she is completing her Ph.D. in Education with an emphasis in Curriculum and Instruction. She has earned ABD status, and for her dissertation she is studying adult twins' relationship and student development in college. She has a Master of Arts degree in Speech Communication and a Bachelor of Science in Elementary Education from Southern Illinois University Edwardsville. She is a presenter at the Mid-Western Educational Research Association and for the Central States and Southern States Communication Associations, and has published articles in both education and communication journals. E-mail: dspudich@slu.edu

Sarah E. Laux, MA, is Assistant Director for Civic Engagement in the Kimmel Leadership Center at Southern Illinois University Edwardsville. A recipient of the ACPA College Student Educators International Disability Ally Award, her areas of work and research include student development, social justice, community service, and civic engagement among college students. E-mail: $\underline{\text { sarah.laux@gmail.com }}$

\section{REFERENCES}

1. Americans with Disabilities Act of 1990, 42 U.S.C. 12101 et seq. Retrieved August 6, 2011, from http://www.ada.gov/pubs/ada.htm

2. Americans with Disabilities Act Amendments Act of 2008, Public Law 110-325, 42 U.S.C § 12102 (2008). Retrieved August 6, 2011, from www.law.georgetown.edu/archiveada/documents/ADAAACR9.17.08.pdf

3. Ash, A., Bellew, J., Davies, M., Newman, T., \& Richardson, L. (1997). Everybody in? The experience of disabled students in further education. Disability \& Society, 12, 605-621. 
4. Barga, N. K. (1996). Students with learning disabilities in education: Managing a disability. Journal of Learning Disabilities, 29, 413-421.

5. Brown, P., \& Levinson, S. C. (1987). Politeness: Some universals in language usage. Cambridge, UK: Cambridge University Press.

6. Bruce, S., Godbold, E., \& Naponelli-Gold, S. (2004). An analysis of communicative functions of teachers and their students who are congenitally deaf blind. Review, 26, 81-90.

7. Charlton, C., Dearing, K., Berry, J., \& Johnson, M. (2008). Nurse practitioners' communication styles and their impact on patient outcomes: An integrated literature review. Journal of the American Academy of Nurse Practitioners, 20, 382-388.

8. Correa-Torres, S. (2008). The nature of the social experiences of students with deaf-blindness who are educated in inclusive settings. Journal of Visual Impairment \& Blindness, 10, 272-283.

9. de Vries, R., Bakker-Pieper, A., Siberg, R., van Gameren, K., \& Vlug, M. (2009). The content and dimensionality of communication styles. Communication Research, 36, 178-206.

10. Duthler, K. W. (2006). The politeness of requests made via email and voicemail: Support for the hyperpersonal model. Journal of Computer-Mediated Communication, 11, 1-24. Edmondson, J. (2009). Let's be clear: How to manage communication styles. $T+D, 63,30-31$.

11. Elliott, M., Gonzalez, C., \& Larsen, B. (2011).U.S. military veterans transition to college: Combat, PTSD, and alienation on campus. Journal of Student Affairs Research and Practice, 48(3), 279-296. doi:10.2202/1949-6605.6293

12. Emery, R., \& Wiseman, R. (1987). An intercultural understanding of able-bodied and disabled persons' communication. International Journal of Intercultural Relations, 11, 7-28.

13. Evans, N., Assadi, J, Herriott, T. (2005). Encouraging the development of disability allies. New Directions for Student Services, (110), 67-79.

14. Evans, N. \& Herriott, T. (2009). Philosophical and theoretical approaches to disability In A. Mitchell \& J. Higbee, (Eds.), Making good on the promise: Student affairs professionals with disabilities. Lanham, MD: University Press of America.

15. Fiedler, C., \& Danneker, J. (2007). Self-Advocacy instruction: Bridging the research-to-practice gap. Focus on Exceptional Children, 39, 1-20.

16. Field. S. (1996). Self-determination instructional strategies for youth with learning disabilities. Journal of Learning Disabilities. 29, 40-51.

17. Fujimori, M., Parker, P., Akechi, T., Sakano, Y., Baile, W., \& Uchitomi, Y. (2007).Japanese cancer patients' communication style preferences when receiving bad news. Psycho-Oncology, 16, 617-625.

18. Garrison-Wade, D., \& Lehmann, J. (2009). A conceptual framework for understanding students' with disabilities transition to community college. Community College Journal of Research \& Practice, 33, 417445.

19. Goff, E. \& Higbee, J. (Eds.). (2008). Pedagogy and Student Services for Institutional Transformation: Implementation Guidebook (Book 1, Book 2). Retrieved August 9, 2011, from http://www.cehd.umn.edu/passit

20. Goffman, E. (1959). The presentation of self in everyday life. New York, NY. Doubleday.

21. Goffman, E. (1967). Interaction ritual: Essays on face-to-face behavior. Chicago, IL: Adrine.

22. Grossman, P. (2009). Foreword with a challenge: Leading our campuses away from the perfect storm. Journal of Postsecondary Education and Disability, 22, 4-9.

23. Haller, B. (2003). DSQ Symposium, Disability \& Humor, Disability Studies Quarterly, 23(3).Available online at: http://www.dsq-sds.org

24. Hanke, S. (2009). Communication styles: What is your impact on others? Professional Safety, 54, $22-25$.

25. Higbee, J. L. (Ed.). (2003). Curriculum transformation and disability: Implementing universal design in higher education. Minneapolis: University of Minnesota, General College, Center for Research on Developmental Education and Urban Literacy. Retrieved October 30, 2007, from http://www.education.umn.edu/crdeul

26. Higbee, J. \& Goff, E. (Eds.). (2008). Pedagogy and Student Services for Institutional Transformation: Implementing Universal Design in Higher Education. Minneapolis, Minnesota. Center for Research on Developmental Education and Urban Literacy.

27. Higher Education Opportunity Act (2008). PL 110-315. Retrieved August 9, 2011, from http://www2.ed.gov/policy/highered/leg/hea08/index.html 
28. Holmes, J. (2000). Politeness, power and provocation: How humour functions in the workplace. Discourse Studies, 2, 159-185.

29. Johns, B., \& McGrath, M. (2008). Be careful what you say: Respecting the privacy rights, equity, and dignity of individuals with special needs. Delta Kappa Gamma Bulletin, 75, 20-26.

30. Johnson, D. M., \& Fox, J. A. (2003). Creating curb cuts in the classroom: Adapting universal design principles to education. In. J. L. Higbee (Ed.), Curriculum transformation and disability: Implementing universal design in higher education. Center for Research on Developmental Education and Urban Literacy, General College, University of Minnesota.

31. Jones, S. R. (1996). Toward inclusive theory: Disability as a social construction. NASPA Journal, 33, 347354.

32. Lightfoot, J. (2009). Student communication preferences in a technology-enhanced learning environment. International Journal of Instructional Media, 36, 9-20.

33. Lim, T. S., \& Bowers, J. W. (1991). Facework: Solidarity, approbation, and tact. Human Communication Research, 17, 415-449.

34. Linton, S. (2006). My body politic, a memoir. Ann Arbor, MI: The University of Michigan Press.

35. Longcope, P. (1995). The universality of face in Brown and Levinson's Politeness Theory: A Japanese perspective. University of Pennsylvania Working Papers in Educational Linguistics, 11, 69 - 79.

36. Madaus, J. W. (2000). Services for postsecondary students with disabilities: A Historical perspective. Journal of Postsecondary Education and Disability, 14, 4-21.

37. McCarthy, D. (2007). Teaching self-advocacy to students with disabilities. About Campus, 12, 10-16.

38. Miles, D. (2010). Officials tout post-9/11 bill benefits. Retrieved from http://www.defense.gov/news/newsarticle.aspx?id=61337

39. Myers, K. A. (2009). College students with visual disabilities: Preferences for effective interaction. Germany: VDM Publishers.

40. Myers, K. \& Bastian, J. (2010). Understanding communication preferences of college students with visual disabilities. Journal of College Student Development, 51(3), 265-278.

41. Myers, K., Jenkins, J., \& Pousson, J. M. (2009). Social norming and disability. ACPA Developments, 9(2). Retrieved from http://www.myacpa.org/pub/developments/archives/2009/Summer/article.php?content=myersa

42. Oetzel, J., Ting-Toomey, S., Chew-Sanchez, M., Harris, R., Wilcox, R., \& Stumpf, S. (2003). Face and facework in conflicts with parents and siblings: A cross-cultural comparison of Germans, Japanese, Mexicans, and U.S. Americans. Journal of Family Communication, 3, 67-93.

43. Raue, K., and Lewis, L. (2011). Students With Disabilities at Degree-Granting Postsecondary Institutions (NCES 2011-018). U.S. Department of Education, National Center for Education Statistics. Washington, DC: U.S. Government Printing Office.

44. Rauscher, L. \& McClintock, M. (1997). Ableism curriculum design. In M. Adams, L.A. Bell, \& P. Griffin (Eds.), Teaching for diversity and social justice (pp. 198-229). New York: Routledge.

45. Reid, D., Stoughton, E., \& Smith, R. (2006). The humorous construction of disability: 'Stand up' comedians in the United States. Disability \& Society, 21, 629-643.

46. Richardson, J., \& Woodley, A. (2001). Approaches to studying and communication preferences among deaf students in distance education. Higher Education, 42, 61-83.

47. Roy, A., \& MacKay, G. (2002). Self-perception and locus of control in college students with different types of vision loss. Journal of Visual Impairment \& Blindness, 96, 254-66.

48. Schreiner, M. B. (2007). Effective self-advocacy: What students and special educators need to know. Intervention in School and Clinic, 42, 300-304.

49. Snyder, T., and Dillow, S. (2010). Digest of Education Statistics 2009 (NCES 2010-013), (Table 231). National Center for Education Statistics, Institute of Education Sciences, U.S. Department of Education. Washington, DC.

50. Test, D. W., Fowler, C. H., Wood, W.M., Brewer, D. M., \& Eddy. S. (2005). A conceptual framework of self-advocacy for students with disabilities. Remedial and Special Education. 26, 43-54.

51. Ting-Toomey, S. (2004). The matrix of face: An updated face-negotiation theory. In W. Gundykunst (Ed.), Theorizing about intercultural communication (pp. 71-94). Newbury Park, CA: Sage Publishers. 
52. Ting-Toomey, S. (1988). Intercultural conflict styles: A face-negotiation theory. In Y Y. Kim \& W. Gundykunst (Eds.), Theories in intercultural communication (pp. 213-235). Newbury Park, CA: Sage Publishers.

53. Ting-Toomey, S., \& Kurogi, A. (1998). Facework competence in intercultural conflict: An updated facenegotiation theory. International Journal of Intercultural Relations, 22, 187-225.

54. Ting-Toomey, S., Oetzel, J., \& Yee-Jung, K. (2001). Self-construal types and conflict management styles. Communication Reports, 14, 87.

55. Tripoli, L., Mellard, D. F., \& Kurth, N. K. (2004). The individual accommodations model (IAM): Accommodating students with disabilities in postsecondary settings. Lawrence: University of Kansas, Center for Research on Learning.

56. Tuttle, D. W. (1984). Self-esteem and adjusting with blindness. Springfield, IL: Charles C. Thomas. In Roy, A. W. \& Mackay, G. F. (2002). Self-perception and locus of control in visually impaired college students with different types of vision loss. Journal of Visual Impairment \& Blindness, 96, 254-66.

57. Vorhaus, J. (2006). Respecting Profoundly Disabled Learners. Journal of Philosophy of Education, 40, 313-328.

58. Wagner, M., D’Amico, R., Marder, C., Newman, L. \& Blackorby, J. (1992). What happens next? Trends in post-school outcomes of youth with disabilities: The second comprehensive report from the National Longitudinal Transition Study of Special Education Students. Menlo Park, CA: SRI International. 


\section{NOTES}

